\title{
O mercado da previdência privada aberta no Brasil ${ }^{1}$ / The market of open-ended private pension in Brazil
}

HenRique Rozendo ${ }^{2}$

Resumo: $\mathrm{O}$ artigo debate a previdência privada aberta como uma mercadoria que, por meio do capital que porta juros, garante o processo de produção e reprodução do capital. Analisa, também, a sua expansão como parte da proposta de 'reforma' previdenciária em curso, tendo no Estado um agente importante para a garantia da sobrevivência das instituiçôes que operam com este produto.

Palavras-chave: previdência privada aberta; seguro; mercadoria.

Abstract: This paper discusses open-ended private pension as a commodity that, by means of interest-bearing capital, guarantees the process of production and reproduction of capital. It also analyzes its expansion as part of the social security 'reformation' proposal underway, having on the State an important agent to ensure the survival of the institutions which operate with this product.

Keywords: open-ended private pension; security; commodity.

\begin{abstract}
A política previdenciária no Brasil tem sido discutida de várias Aformas e com prismas analíticos distintos, que perpassam, de um lado, pela compreensão econômica aparentemente deficitária desta política, na qual resultaria na necessidade de reformá-la e, por outro lado, de uma análise a partir da crítica da economia política, capaz de desmistificar e revelar o papel que a previdência assume nos marcos da
\end{abstract}

1 O presente trabalho é fruto do nosso objeto de estudo no Doutorado em Serviço Social da UFRJ, sob a orientação da profa Sara Granemann.

2 Doutorando em Serviço Social pela Universidade Federal do Rio de Janeiro (UFRJ). Bolsista Capes. Professor do Curso de Serviço Social da Universidade Federal do Recôncavo da Bahia (UFRB). 
realidade brasileira, sobretudo quando esta tem se tornado fonte necessária para o processo de acumulação e reprodução do capital.

De partida, entendemos que as políticas sociais devem ser pensadas como a forma pela qual o Estado intervém nas expressóes da questão social, ${ }^{3}$ na mediação do embate entre o capital e o trabalho. Aludimos, assim, neste texto, que ao falarmos sobre previdência privada, especificamente a aberta, consideramos ser esta uma forma de seguro pela qual o grande capital se apropria da riqueza produzida pelo trabalho não pago, a fim de transformá-la em capital que porta juros. Tratase de uma negação da política social, uma "não previdência" (GRANEMANN, 2006), que necessita da política previdenciária pública para expandir seus negócios e garantir a sua rentabilidade.

Demarcamos, assim, que a previdência privada não é uma expressão de luta da classe trabalhadora por melhorias na sua condição de vida, mas justamente se revela como um mecanismo pelo qual o capital aprofunda a exploração da força de trabalho, contribuindo para a alienação da classe trabalhadora, que passa a entender a previdência privada como uma saída possível para a garantia da proteção social.

Neste sentido, as aproximaçóes advindas a partir das nossas inquietaçóes de pesquisa sobre a previdência privada aberta partem da realidade como método expositivo capaz de deslindar este tipo de mercadoria. Com isso, o presente trabalho tem por objetivo apresentar o debate sobre a previdência privada aberta na realidade brasileira, bem como tecer algumas consideraçóes sobre como tal mercadoria vem sendo posta à venda aos/às trabalhadores/as, tendo no Estado um agente importante para a garantia da sobrevivência das instituiçóes financeiras que operam com este produto.

\section{A atividade seguradora no Brasil}

Data do período do Império a primeira companhia autorizada a funcionar no país, a Companhia de Seguros Boa Fé, que tinha por objetivo operar no seguro marítimo, sendo regulada pela Casa de

3 Netto ([1992] 2007) sinaliza que só é possível pensar em política social pública na sociedade burguesa com a emergência do capitalismo monopolista. 
Seguros de Lisboa. Com a promulgação do Código Comercial Brasileiro, pela Lei no 556, de 1850, tivemos o desenvolvimento do seguro no Brasil, que incentivou o aparecimento de inúmeras seguradoras que passaram a operar não só com o seguro marítimo, expressamente previsto na legislação, mas, também, com o seguro terrestre.

Demarca-se que o Código Comercial proibia o seguro sobre "a vida de alguma pessoa livre", restando claro que só se podia fazer seguro de vida sobre o escravo, sendo este considerado uma mercadoria. O seguro de vida, proibido expressamente pelo Código Comercial, foi autorizado em 1855 .

Com a expansão do setor, as empresas de seguros estrangeiras começaram a se interessar pelo mercado brasileiro e transferiam para suas matrizes os recursos financeiros obtidos pelos prêmios cobrados, provocando uma significativa evasão de divisas (SUSEP, 1997). O grande volume de capital estrangeiro ${ }^{4}$ nos setores da economia nem sempre foi visto como aceitável pela elite brasileira. Deste modo, a promulgaçáo do Decreto no 294, de 1895, que dispunha exclusivamente sobre as companhias estrangeiras de seguros de vida que funcionavam no país, obrigava-os a empregar o total das reservas técnicas em bens e em valores nacionais.

A legislação nos anos seguintes regulou o funcionamento das companhias de seguros já existentes ou que viessem a se organizar no território nacional. O Regulamento Murtinho ${ }^{5}$ criou o primeiro órgão fiscalizador oficial da atividade de seguros: a Superintendência Geral de Seguros, ${ }^{6}$ subordinada diretamente ao Ministério da Fazenda. Cabe destacar que o referido decreto proibia que companhias de seguros de vida realizassem seguros terrestre e marítimo e vice-versa.

4 Segundo Costa (2001) o número de sociedades anônimas a funcionar no Brasil, no período de 1899 e 1910, era em torno de 41 empresas nacionais contra 160 estrangeiras.

5 O Decreto $n^{\circ} 4.270$, de 10 de dezembro de 1901, ficou assim conhecido por ser regulamentado pelo entáo ministro da Fazenda Joaquim Murtinho, no governo do presidente Campo Sales (1898-1902).

6 Posteriormente, pelo Decreto $n^{\circ}$ 5.072, de 12 de dezembro de 1903, a Superintendência Geral de Seguros foi substituída por uma Inspetoria de Seguros, também subordinada ao Ministério da Fazenda, com a mesma sistemática que teria a superintendência. 
O Código Civil Brasileiro, de 1916, avançou no ordenamento jurídico sobre o contrato de seguros, apontando que "a vida e as faculdades humanas também se podem estimar como objeto segurável, e segurar, no valor ajustado, contra os riscos possíveis, como o de morte involuntária, inabilitação para trabalhar ou outros semelhantes".

Em 1919, no período pós-primeira guerra mundial, o Congresso aprovou a Lei de Acidentes de Trabalho que tornava obrigatório o seguro de acidentes em todas as empresas industriais, contribuindo assim para o crescimento do mercado segurador. Com a Lei Eloy Chaves, de 1923, teve-se o início de uma maior intervenção do Estado na sociedade com a criação das Caixas de Aposentadorias e Pensóes (CAPs), excluindo as seguradoras da participação em um mercado com grandes possibilidades de lucros. (COSTA, 2001).

As Constituições brasileiras de 1934 e 1937 instituíram o "princípio da nacionalização do seguro", impulsionado pelo movimento da realidade brasileira vivenciada pelo "Estado Novo" no governo do presidente Getúlio Vargas. Iniciou-se, assim, uma nova era nacionalista que modificaria as estruturas do mercado segurador brasileiro.

Em 1939, foi criado o Instituto de Resseguros do Brasil (IRB), via Decreto-Lei $\mathrm{n}^{\circ} 1.186$, o qual estabeleceu que, a partir de então, as sociedades seguradoras ficavam obrigadas a ressegurar no IRB as responsabilidades que excedessem sua capacidade de retenção própria. O governo federal procurou, assim, evitar que grande parte das divisas fosse enviada para o exterior.

No ano posterior, tivemos a regulamentação das operações de seguros privados e sua fiscalização, pelo Decreto-Lei no 2.063 de 1940, realizadas por sociedades anônimas, mútuas e corporativas. Estas sociedades poderiam funcionar em dois grupos definidos: seguro dos ramos elementares e seguro de vida. Em 1964, a reforma bancária classificou as seguradoras como investidores institucionais. ${ }^{7}$

7 Segundo Fortuna (2015), os investidores institucionais "constituem um tipo de investidor que, por gerenciar recursos de terceiros, e/ou garantir suas obrigaçóes contratuais com terceiros, deve aplicar os recursos que dispóe de acordo com as regras previamente definidas pela entidade fiscalizadora do seu segmento de atividade. Podem ser agrupadas em fundos mútuos de investimentos, entidades abertas e fechadas de previdência complementar e seguradoras”. (p. 43). 
Por intermédio do Decreto-Lei no 261, de 1967, e da Lei no 6.435 , de 1977, é que foram regulados respectivamente as sociedades de capitalização e as entidades de previdência privada, estas prevendo a garantia pelo Estado da segurança econômico-financeira dos planos de benefícios e das entidades de previdência, no intuito de propiciar uma integração dos processos sociais e econômicos do país.

A Lei Complementar no 109, de 29 de maio de 2001, substituiu a Lei $\mathrm{n}^{\circ}$ 6.435, de 1977, destacando o caráter facultativo e eminentemente complementar deste tipo de 'previdência', sendo organizado de forma autônoma ao regime geral de Previdência Social. A organização da previdência privada passa a se constituir por meio de duas modalidades: as Entidades Fechadas de Previdência Complementar (EFPC) e as Entidades Abertas de Previdência Complementar (EAPC).

As entidades fechadas, também conhecidas como fundos de pensão, ${ }^{8}$ destinam-se aos trabalhadores de uma determinada empresa ou de um grupo delas, e aos servidores da União, dos estados, do Distrito Federal e dos municípios. A Superintendência Nacional de Previdência Complementar (Previc) é responsável por fiscalizar suas atividades. As entidades abertas são constituídas unicamente sob a forma de sociedades anônimas e têm por objetivo instituir e operar planos de benefícios de caráter previdenciário acessíveis a qualquer pessoa física. $\mathrm{O}$ órgão do governo que fiscaliza e regula os planos de previdência privada aberta é a Superintendência de Seguros Privados (Susep), ligada ao Ministério da Fazenda.

\section{A mercadoria previdência privada aberta}

O ponto de partida para entendermos a lógica da previdência privada, especificamente a aberta, dá-se na compreensão desta como um tipo de mercadoria que, por um lado, se apresenta possuidora de valor de uso, pois para o trabalhador se garantiria uma aposentaria segura, tendo em vista que com o aparente déficit ${ }^{9}$ da Previdência

8 Para um maior aprofundamento sobre os fundos de pensão ver Granemann (2006) e Maia (2003).

9 Sobre a desmistificação do déficit previdenciário brasileiro é fundamental a leitura de Gentil (2006) sobre "A política fiscal e a falsa crise da seguridade social brasileira - análise financeira do período 1990-2005”. 
Social pública se tornaria necessário investir em uma nova mercadoria, como a previdência privada; por outro lado, apresenta-se como valor de troca que, ao se realizar na esfera da circulação a compra e venda de mercadorias, fornece para o capitalista um volume de capital a ser empregado no setor financeiro.

Há aqui presente o caráter alienado desta mercadoria para a consciência da classe trabalhadora, pois passa a encobrir o papel que esta assume na dinâmica do sistema capitalista. Para Granemann (2006) "a 'renda' ${ }^{10}$ do trabalho transformada e convertida em capital por obra da 'previdência privada' presta-se a atuar, fundamentalmente, como capital portador de juros estimulador da especulação, nos mais distintos pontos do planeta”. (p. 51).

Para Marx, em seu Livro III de $O$ capital, esse movimento típico do capital comércio de dinheiro faz com que, em um nível de abstração elevado, apresente o dinheiro com mais uma dimensão, a de funcionar como capital. A essa forma específica de mercadoria-capital, Marx denomina de capital portador de juros.

Dinheiro - considerado aqui como expressáo autônoma de uma soma de valor, exista ela de fato em dinheiro ou em mercadorias - pode na base da produção capitalista ser transformado em capital e, em virtude dessa transformação, passar de um valor dado para um valor que se valoriza a si mesmo, que se multiplica. Produz lucro, isto é, capacita o capitalista a extrair dos trabalhadores determinado quantum de trabalho não pago, mais produto e mais-valia, e apropriar-se dele. Assim adquire, além do valor de uso que possui como dinheiro, um valor de uso adicional, a saber, o de funcionar como capital. Seu valor de uso consiste aqui justamente no lucro que, uma vez transformado em capital, produz. Nessa qualidade de capital possível, de meio para a produção de lucro, torna-se mercadoria, mas uma mercadoria sui generis. $\mathrm{Ou}$, o que dá no mesmo, o capital enquanto capital se torna mercadoria. (MARX, 1986, p. 255, grifo nosso).

10 Granemann (2006) aponta que o salário do trabalhador passa a ser convertido em "renda", como assim desejou a economia clássica e os demais pensamentos econômicos atuais, renda esta em favor do capital, apropriada por ele e transformada em capital. 
Aqui encontramos conexão entre a previdência privada aberta e a mercadoria-capital, tendo em vista que esta possibilita que a "instituição financeira/prestatário" invista parte do salário do "trabalhador/ prestamista" como um capital que se valoriza na esfera da circulação por meio da especulaçáo financeira, agilizando o processo de rotação do capital, para que as mercadorias e o próprio dinheiro não fiquem em alqueive. ${ }^{11}$ Assim, a previdência privada aberta ao movimentar o mundo das finanças, em especial pelo volume de dinheiro que esta póe em circulação, canaliza estes recursos para as instituiçóes financeiras, a fim de transformá-los em capital que porta juros.

Assim, as medidas de ajustes estruturais que incidem diretamente sobre a Previdência Social visam, por um lado, restringir a Previdência Social pública e ampliar a previdência privada; por outro, transformar os recursos da previdência em capital portador de juros, seja mediante os investimentos dos fundos de pensão, seja por meio da previdência complementar aberta, entre outros. Atingir a Previdência Social se tornou meta desses ajustes, tendo em vista ser esta uma política social de caráter contributivo direto e que, por isso, arrecada um volume imenso de recursos. Desmontar a Previdência Social e canalizar os seus recursos para serem financeirizados é meta a ser alcançada pelo grande capital.

O papel do Estado, assim, passa a assumir centralidade na garantia do acordo contratual entre o trabalhador e as instituiçóes financeiras. Com a Lei Complementar no 109 de 2001 fica estabelecido que a ação do Estado objetiva, dentre outros elementos, "determinar padróes mínimos de segurança econômico-financeira e atuarial, com fins específicos de preservar a liquidez, a solvência e o equilíbrio dos planos de benefícios, isoladamente, e de cada entidade de previdência complementar".

No Brasil, as operaçóes de planos com cobertura por sobrevivência oferecida em plano de seguro de vida é regulada, basicamente, pela Resolução CNSP 140/2005 (com redação alterada pela Resolução CNSP 148/2006) e pelas Circulares SUSEP 338/2007 - planos de previdência complementar, e 339/2007 - planos de seguro de pessoas.

11 Marx (1986) apresenta duas formas do capital de comércio de dinheiro, a de funcionar como tesouro, um fundo de reserva para meios de pagamento e de compra, e a de capital em alqueive, momentaneamente desocupado e ainda não investido. 
A cobertura por sobrevivência, conforme Resolução CNSP 140/2005, opera nas seguintes modalidades: contribuição variável e benefício definido.

I - Contribuição variável: em que o valor e o prazo de pagamento de prêmios podem ser definidos previamente e o capital segurado, pagável de uma única vez ou sob a forma de renda, por ocasião da sobrevivência do segurado ao período de diferimento, é calculado com base no saldo acumulado da respectiva provisão matemática de benefícios a conceder e no fator de cálculo;

II - Benefício definido: em que o capital segurado, pagável de uma única vez ou sob a forma de renda, e os respectivos prêmios são estabelecidos previamente na proposta (ou propostas).

Entre os planos mais conhecidos da previdência privada aberta, conforme a Susep, estão o Vida Gerador de Benefícios Livres (VGBL) e o Plano Gerador de Benefícios Livres (PGBL). O VGBL é classificado como seguro de pessoa, tendo características previdenciárias, enquanto o PGBL é um plano tradicional de previdência complementar. As aplicaçóes dos recursos destes tipos de fundos variam dos mais agressivos, que investem em renda variável (açóes), aos mais conservadores, que aplicam apenas em títulos públicos e/ou títulos privados.

O tratamento tributário seria, segundo a Susep, a principal diferença entre os dois tipos de planos. No caso do PGBL, os participantes que utilizam o modelo completo de declaração de ajuste anual do Imposto de Renda de Pessoa Física (IRPF) podem deduzir as contribuições do respectivo exercício, no limite máximo de $12 \%$ de sua renda bruta anual. No momento do resgate, a tributação no PGBL se dá sobre todo o valor (contribuiçóes mais rendimentos).

No caso do VGBL, os prêmios/contribuições pagos não podem ser deduzidos na declaração de ajuste anual do IRPF, recomendado, segundo as instituiçóes reguladoras, para aqueles que utilizam o modelo simplificado de declaração de ajuste anual do IRPF. Ao ser resgatado, a tributação do Imposto de Renda no VGBL ocorrerá sobre os rendimentos obtidos no respectivo plano. Importante demarcar, também, que tanto com o VGBL como o PGBL não se tem a garantia de remuneraçáo mínima e de atualização de valores, sendo sempre estruturados na modalidade de contribuição variável. 
A Confederação Nacional de Empresas de Seguros Gerais, Previdência Privada e Vida, Saúde Suplementar e Capitalização (CNSEG) ${ }^{12}$ aponta que, em 2015, a participação do setor segurador brasileiro no PIB passou a representar $6,18 \%$ com uma produção global de $\mathrm{R} \$$ 364,98 bilhóes, apresentando um crescimento desde 2011, quando este representava cerca de $4,98 \%$ do PIB.

Dos mercados supervisionados pela Susep ${ }^{13}$ - seguros, previdência e capitalização - estes correspondiam, em 2015, a 3,71\% do PIB com uma produção de 219 bilhóes de reais. Segundo a Federação Nacional de Previdência Privada e Vida (FenaPrevi), os prêmios e contribuiçóes pagos para Seguros de Pessoas e Planos de Benefícios de Previdência Complementar Aberta somaram, em 2015, R\$ 128,79 bilhôes. $\mathrm{O}$ valor total arrecadado (nominal) representou $2,18 \%$ do PIB, apresentando um crescimento real de 4,5\% em relação a 2014, como se pode observar na tabela abaixo:

Tabela 1 - Arrecadação e participação no PIB de coberturas de pessoas por tipo de plano, em $\mathrm{R} \$$ bilhóes e $\%$ de participação

\begin{tabular}{lccccc}
\hline \multicolumn{1}{c}{ Tabela 1 } & $\mathbf{2 0 1 1}$ & $\mathbf{2 0 1 2}$ & $\mathbf{2 0 1 3}$ & $\mathbf{2 0 1 4}$ & $\mathbf{2 0 1 5}$ \\
Plano de Risco & & 24,34 & 28,60 & 30,73 & 32,79 \\
\hline Plano de Acumulação & 51,44 & 68,12 & 71,10 & 80,66 & 96,00 \\
Cobertura de Pessoas & 72,78 & 92,46 & 99,70 & 111,39 & 128,79 \\
PIB & $4.373,70$ & $4.805,90$ & $5.316,50$ & $5.687,30$ & $5.904,30$ \\
$\begin{array}{l}\text { Penetração do setor no } \\
\text { PIB }\end{array}$ & $1,76 \%$ & $2,11 \%$ & $2,06 \%$ & $2,17 \%$ & $2,18 \%$ \\
\hline
\end{tabular}

Fonte: CNSEG. Informe Anual Mercado Segurador Brasileiro, 2015

${ }^{1}$ Os planos de risco são os seguros coletivos e individuais

${ }^{2}$ Os planos de acumulação se referem aos da família PGBL e VGBL

12 Ver: CNSEG. Mercado segurador brasileiro: resultados e perspectivas. 2015.

13 Os valores relativos ao segmento de seguro saúde se encontram sob a supervisão da Agência Nacional de Saúde Suplementar (ANS), desde agosto/2001. 
É na região Sudeste do país que existe a maior contribuição para o custeio de Planos de Risco e de Acumulaçáo de Seguros de Pessoas e para Planos de Benefícios de Previdência Complementar Aberta, onde foram pagos $67 \%$ do valor total das contribuiçóes e prêmios, seguida da região Sul, com 15\%; da regiáo Nordeste, com 9,7\%; da região Centro-Oeste, com 6,7\%; e da região Norte, com apenas $1,7 \%$. (CNSEG, 2015).

O VGBL, quando foi regulamentado pela Susep, em 2002, passou a ter uma aceitabilidade pelo mercado de seguros, passando, em 2014, a representar, juntamente com o seguro de pessoas, $60,3 \%$ do mercado de seguros fiscalizados pela Susep naquele ano. ${ }^{14}$

Os dados do balanço do $3^{\circ}$ trimestre de 2016 da FenaPrevi apontam que as contribuiçóes dos planos abertos de caráter previdenciário (que incluem os PGBLs e os VGBLs) somaram R $\$ 26,07$ bilhóes, que resultaram em uma evolução de $24,02 \%$ frente ao mesmo período do ano anterior. (FENAPREVI, 2016).

Nos primeiros nove meses de 2016, de janeiro a setembro, ainda segundo a FenaPrevi, os aportes acumularam R \$ 78,04 bilhōes (VGBL - $\mathrm{R}$ \$ 71,72 bilhóes, PGBL - R \$ 5,69 bilhóes e os planos tradicionais de acumulação - R \$ 627,05 milhôes), apresentando uma evolução de $16,4 \%$ frente ao mesmo período do ano passado.

Como parte deste trabalho em revelar a mercadoria previdência privada aberta no Brasil, é oportuno conhecermos as instituições que tiveram uma maior contribuiçáo em planos abertos de previdência, de janeiro a novembro de 2016, que evidencia conforme a tabela $2 \mathrm{em}$ uma predominância dos grandes grupos econômicos, especialmente do setor bancário.

14 Ver: Susep: $3^{\circ}$ Relatório de Análise e Acompanhamento dos Mercados Supervisionados, 2015. 
Tabela 2 - Contribuiçóes em planos abertos de previdência (VGBL e PGBL - jan. a nov./2016)

\begin{tabular}{lc}
\hline \multicolumn{1}{c}{ Empresa } & Contribuiçóes (R\$) \\
\hline Brasilprev Seguros e Previdência S/A & $40.797 .617 .324,00$ \\
Bradesco Vida e Previdência S.A. & $23.447 .120 .101,00$ \\
Itaú Vida e Previdência S.A. & $17.823 .431 .073,00$ \\
Caixa Vida e Previdência S.A. & $6.371 .429 .274,00$ \\
Zurich Santander Brasil Seguros e Previdência S.A. & $4.597 .282 .249,00$ \\
Kirton Vida e Previdência S.A. & $1.318 .822 .507,00$ \\
Icatu Seguros S.A & $866.977 .046,00$ \\
Safra Vida e Previdência S.A. & $646.938 .772,00$ \\
\hline Sul América Seguros de Pessoas e Previdência S.A. & $442.228 .953,00$ \\
Porto Seguro Vida e Previdência S/A. & $319.084 .011,00$ \\
\hline Outras Empresas* & $813.527 .609,00$ \\
\hline Total & $97.444 .458 .919,00$ \\
\hline
\end{tabular}

Fonte: Sistema de Estatísticas da Susep, 2016

*Representam 14 empresas que operam com VGBL e/ou PGBL

Nota-se, com isso, que as grandes instituiçóes bancárias controlam um volume considerável de dinheiro proveniente da exploração da força de trabalho. O Estado, ao não garantir efetivamente um sistema de proteção social eminentemente público, tem investido de forma cada vez mais perversa no alargamento da previdência privada, que faz com que trabalhadores ao longo do seu período laboral onerem ainda mais o seu salário, ao "investir" parte deste no mercado de seguros previdenciários. 


\section{A Proposta de Emenda à Constituiçáo no 287/2016: um alento ao "nervosismo"15 do mercado de previdência privada}

As discussões sobre a 'reforma'16 da Previdência Social passaram novamente a ser pauta de debate no Congresso Nacional com a PEC n ${ }^{\circ}$ 287, de 05 de dezembro de 2016, na qual pontuam sobre mudanças no sistema de seguridade social, no intuito de dilacerar a passos rápidos a Previdência Social pública.

As principais mudanças contidas nessa Proposta de Emenda à Constituição dizem respeito ao estabelecimento da idade mínima para aposentadoria aos 65 anos de idade, para homens e mulheres, atrelado ao mínimo de 25 anos de contribuição; regra de transição para homens com 50 anos e mulheres com 45 anos de idade; necessidade dos estados e municípios aprovarem planos de previdência complementar sob pena de sanção; aperfeiçoamento dos regimes próprios de Previdência Social; contribuição do trabalhador rural ao regime de previdência, com a contribuição mensal ainda a ser definida por Lei; e a desindexação ao salário mínimo do Benefício de Prestação Continuada (BPC) e o aumento da idade de 65 para 70 anos.

Todas essas questóes colocadas pela presente PEC fazem derruir a Previdência Social pública, bem como as outras políticas ligadas à seguridade social, como a saúde e assistência social, tendo em vista que a estas se relacionam a Emenda Constitucional no 95 que institui o Novo Regime Fiscal, que comumente ficou conhecida como a PEC do teto dos gastos públicos.

Desta feita, qual a relação desta 'reforma' como o mercado da previdência privada, especificamente a aberta?

15 Há por parte de alguns estudiosos da esfera econômica certa personificação do mercado financeiro, sendo este considerado um sujeito que possui estados emocionais distintos, a depender da situação econômica vigente, tanto é que nos parece frequente a utilização dos termos de mercado "nervoso", "calmo", "aquecido" etc., para nomear o que se passa por trás das transaçóes financeiras.

16 Utilizamos 'reforma' entre aspas por entendermos, corroborando a análise de Behring (2003), que se trata de apropriação indébita e fortemente ideológica da ideia reformista, destituindo-se de seu conteúdo progressista, assim, o que se configura na realidade brasileira é uma verdadeira contrarreforma, na perda de direitos. 
Ora, o mercado da previdência privada cresce com a crise da previdência pública, passando o setor público a exercer o papel regulador desse mercado. As matérias veiculadas pelo Valor Econômico, jornal da grande burguesia nacional, são exemplares com relação a esse argumento, vejamos:

"Rumo à privatização da aposentadoria" (09/12/2016)
"Reforma aumenta captação privada" (12/12/16)
"Reforma abre espaço para Estados adotarem previdência
privada" (19/12/2016)
"Reforma da previdência: equilíbrio atuarial, mas ainda longe
do justo" (21/12/2016)
"Reforma abre oportunidade para previdência complementar"
$(22 / 12 / 16)$

$\mathrm{Na}$ totalidade das matérias, o seu conteúdo aponta para a necessidade de 'reformar' a previdência pública para o crescimento da previdência complementar, com uma potencial elevação da demanda por planos privados. Em entrevista ao Valor, o secretário da Previdência, Marcelo Caetano, ${ }^{17}$ explicou que a medida tem como objetivo estimular a concorrência entre as instituiçóes aptas a ofertar planos de benefícios para os governos regionais, para auxiliar estados e municípios a escolherem a entidade de previdência que oferece o melhor custo.

Somam-se a estes argumentos, a necessidade de se fixar um teto para o valor dos benefícios, estes já pontuados pelas contrarreformas previdenciárias de 1998 e 2003. O estabelecimento deste teto é uma marca importante para a venda do produto previdência privada aberta, tendo em vista que para o mercado de seguros, esta determinação é responsável por estudos de marketing (Cf. RICIOLLI, 2002) capazes de absorver os trabalhadores que ganham acima do valor estabelecido pelo teto do Regime Geral de Previdência Social. Nesse sentido, rebaixar o valor das aposentadorias da Previdência Social pública é de fundamental importância para o crescimento do mercado de previdência privada.

Assim, acreditamos que estes são alguns dos efeitos desta 'reforma' para "acalmar" o "nervosismo" do mercado de seguros, em especial da

17 Entrevista publicada em 22/12/2016, disponível em: <http://www.valor.com. br/brasil/4811433/reforma-abre-espaco-para-estados-adotarem-previdenciaprivada>. 
previdência privada aberta. Alento aos grandes capitais que poderão capturar ainda mais uma parte do trabalho não pago, por meio da apropriação de parte do salário do(a) trabalhador(a), para futuros investimentos no mundo das finanças.

\section{Consideraçóes finais}

O debate apresentado neste texto procurou revelar que o processo de desajuste do sistema de proteçâo social, bem como das políticas sociais em geral, seguem pela contramão dos direitos sociais, na orientaçâo do grande capital portador de juros em favorecimento ao mercado de seguros (ROZENDO, 2016). Nessa compreensão, a política previdenciária no Brasil vê-se envolta no processo de contrarreforma que restringe e minimiza o acesso aos direitos sociais, abrindo espaço para a previdência privada.

A prática corrente de privatizaçóes dos serviços públicos, altamente atrativos aos capitalistas, bem como os serviços sociais, sobre a premissa de incapacidade do Estado em geri-los são argumento fundamental para contrarreformar as políticas sociais.

Com este cenário, abre-se cada vez mais um mercado de seguros que obstina vender a mercadoria previdência privada aberta aos trabalhadores, para que se possa garantir futuramente uma aposentadoria, com a necessidade de se apropriar de parte do trabalho não pago. Opera-se aqui o fetiche desta mercadoria, ocultando o que de fato ela representa.

Neste campo, a previdência privada aberta aparece como uma face nova para a expansão do mercado de capitais que porta juros. Tem-se, com isso, a materialização da financeirização da política previdenciária que, ao garantir reservas consideráveis aos grandes grupos econômicos, especialmente os bancários, faz com que estes capturem uma parte do salário do trabalhador via contribuição à previdência privada.

No tempo presente, necessário se faz desmistificar a Proposta de Emenda Constitucional no 287/16, sobre a 'reforma' da previdência, para que se reivindique uma ampliaçáo da cobertura previdenciária pública e a garantia da responsabilidade do Estado. Será preciso garantir as fontes 
de financiamento da seguridade social e com isso mexer na estrutura fiscal, a fim de torná-la mais progressiva, ou seja, fazer com que quem recebe mais recurso pague mais. Atualmente, quem paga mais imposto é a classe trabalhadora que ganha menos de dois salários mínimos.

Assim, longe de esgotar o debate sobre a previdência privada aberta, é necessário que estudos sejam amplamente realizados e divulgados à classe trabalhadora, sobre as novas formas pelas quais o grande capital se apropria do trabalho humano em favorecimento das grandes corporaçóes internacionais e dos setores burgueses que desejam mercantilizar até a nossa capacidade de pensar.

Submissão em 30 de novembro de 2016 e aceito para publicaçáo em 30 de dezembro de 2016.

\section{Referências}

BEHRING, E. R. Brasil em contrarreforma. Desestruturação do Estado e perda de direitos. São Paulo: Cortez, 2003.

BRASIL. Proposta de Emenda à Constituição no 287, de 05 de dezembro de 2016. Altera os arts. 37, 40, 109, 149, 167, 195, 201 e 203 da Constituiçáo, para dispor sobre a seguridade social, estabelece regras de transiçáo e dá outras providências. Disponível em: <http://www.camara.gov.br/ proposicoesWeb/fichadetramitacao?idProposicao=2119881>.

CNSEG. Mercado segurador brasileiro: resultados e perspectivas. 2015.

COSTA, Ricardo Cesar Rocha. A atividade seguradora nas primeiras décadas da República. In: ALBERTI, Verena (Coord.). Entre a solidariedade e o risco: história do seguro privado no Brasil. 2. ed. Rio de Janeiro: FGV, 2001.

FENAPREVI. Previdência, $3^{\circ}$ trimestre de 2016. Dados Consolidados. 2016.

FORTUNA, Eduardo. Mercado financeiro: produtos e serviços. 20. ed. Rio de Janeiro: Qualitymark, 2015.

GENTIL, Denise Lobato. A política fiscal e a falsa crise da seguridade social brasileira. Análise financeira do período 1990-2005. Tese de doutorado. Rio de Janeiro: IEconomia/UFRJ. 2006.

GRANEMANN, S. Para uma interpretaçáo marxista da 'previdência privada'. Rio de Janeiro: UFRJ, 2006. (Tese de Doutorado). 
MAIA, Rosana de Almeida. Fundos previdenciários e o financiamento do desenvolvimento: o papel dos fundos patrimoniais dos trabalhadores e dos fundos de pensão. Campinas-SP: Unicamp, 2003. (Tese de Doutorado). MARX, Karl. O capital: crítica da economia política. 2. ed. Livro III, v. IV. São Paulo: Nova Cultural, 1986.

NETTO, José Paulo. Capitalismo monopolista e Serviço Social. 6. ed. São Paulo: Cortez, [1992] 2007.

RICIOLLI, Reginaldo. O marketing de distribuiçáa da previdência complementar aberta. Rio de Janeiro: Funenseg, 2002. (Caderno de Seguros: teses, v. 7, n. 12).

ROZENDO, Henrique. Previdência privada aberta no Brasil: a outra face da contrarreforma. ENCONTRO NACIONAL DE PESQUISADORES EM SERVIÇO SOCIAL, 15. Ribeirão Preto-SP: ABEPSS, 2016.

SUSEP. $3^{\circ}$ Relatório de Análise e Acompanhamento dos Mercados Supervisionados. Superintendência de Seguros Privados (Susep). Comissão de Estudos e Desenvolvimento (CED). 2015. (impresso).

Anuário Estatístico 1997. Seguro-Previdência Privada AbertaCapitalização. 1997. 